SESSION VI

COURTES COMMUNICATIONS ET SÉANCE DE TRAVAIL

\title{
The genetic principles of the continuous hybridization programme
}

\author{
J. KÁRPÁTI \\ Kaposvar, Kanizsai u. 72, 7400, Hungary
}

\begin{abstract}
In the beginning, in the 1950's and 1960's the tone ruling international literature was there are no possibilities for producing hybrids in swine breeding, in contrast to poultry breeding. Since that time more and more experience proved what we can lose by purebred breeding. This breeding method, the continuous pig hybridization shows the most economical way for the goal.

The basic principles of this kind of hybridization : the male line is bred by close inbreeding creating inbred lines, the sows are selected from the "hybrid end product» through a selection process conducted under high genetic pressure to form the next mother generation. In every single case they receive the most suitable male partner based on test mating.
\end{abstract}

\section{Maternal and grand-maternal effects on litter size in pigs}

\author{
G. NITTER, P. ZINSMAIER, Andrea CZAP and H. HAUSSMANN \\ Institut für Tierhaltung und Tierzüchtung, Univ. Hohenheim \\ $D-7000$ Stuttgart 70
}

Two sets of data were available for an investigation of genetic parent-offspring relationships in pig fertility. These were the records of selected lines in a University farm and herdbook data in Baden-Württemberg. Regressions of daughters' litter sizes were calculated separately on their litter of origin and on independent litters of their dams. Furthermore, on a small number of records daughter-granddam regressions could be presented. A comparison of heritabilities derived from these different types of regression partly revealed some evidence of the existence of maternal effects on litter size as originally shown in mice by FALCONER (1965). The insufficiency of this type of analysis was discussed for the problem raised which is particularly relevant in herdbook data.

\section{Heritability of litter size, phenotypic and genetic correlations between the four first litters of Large White sows}

\author{
G. BOLET and C. FELGINES \\ Station de Génétique quantitative et appliquée, I.N.R.A. \\ F 78350 Jouy-en-Josas
}

Data from 76 purebred Large White herds from 1965 to 1979 were used to estimate genetic parameters of litter size characteristics (number of piglets born - NB - born alive - NA - and weaned - NW -) using the daughter-dam regressions for the parities 1 to 4 (21 538 data). Heritabilities go from to 0.01 to 0.12 . Genetic and phenotypic correlations 